\title{
Targeting ATR in vivo using the novel inhibitor VE-822 results in selective sensitization of pancreatic tumors to radiation
}

\author{
E Fokas ${ }^{1,3}$, R Prevo ${ }^{1}$, JR Pollard ${ }^{2}$, PM Reaper ${ }^{2}$, PA Charlton ${ }^{2}$, B Cornelissen ${ }^{1}$, KA Vallis $^{1}$, EM Hammond ${ }^{1}$, MM Olcina ${ }^{1}$, \\ W Gillies McKenna ${ }^{1}$, RJ Muschel ${ }^{1,4}$ and TB Brunner, ${ }^{*, 1,4,5}$
}

Combined radiochemotherapy is the currently used therapy for locally advanced pancreatic ductal adenocarcinoma (PDAC), but normal tissue toxicity limits its application. Here we test the hypothesis that inhibition of ATR (ATM-Rad3-related) could increase the sensitivity of the cancer cells to radiation or chemotherapy without affecting normal cells. We tested VE-822, an ATR inhibitor, for in vitro and in vivo radiosensitization. Chk1 phosphorylation was used to indicate ATR activity, $\gamma \mathrm{H} 2 \mathrm{AX}$ and 53BP1 foci as evidence of DNA damage and Rad51 foci for homologous recombination activity. Sensitivity to radiation (XRT) and gemcitabine was measured with clonogenic assays in vitro and tumor growth delay in vivo. Murine intestinal damage was evaluated after abdominal XRT. VE-822 inhibited ATR in vitro and in vivo. VE-822 decreased maintenance of cell-cycle checkpoints, increased persistent DNA damage and decreased homologous recombination in irradiated cancer cells. VE-822 decreased survival of pancreatic cancer cells but not normal cells in response to XRT or gemcitabine. VE-822 markedly prolonged growth delay of pancreatic cancer xenografts after XRT and gemcitabine-based chemoradiation without augmenting normal cell or tissue toxicity. These findings support ATR inhibition as a promising new approach to improve the therapeutic ration of radiochemotherapy for patients with PDAC.

Cell Death and Disease (2012) 3, e441; doi:10.1038/cddis.2012.181; published online 6 December 2012

Subject Category: Cancer

With a 5-year survival rate of $5 \%$, pancreatic ductal adenocarcinoma (PDAC) is one of the most lethal malignancies. ${ }^{1,2}$ Most patients have locally advanced or metastatic disease at the time of diagnosis. ${ }^{1}$ Chemoradiation was shown to increase resectability and to enhance local tumor control ${ }^{3,4}$ at the cost of gastrointestinal toxicity. ${ }^{5}$ Several trials with targeted agents such as inhibitors of angiogenesis, metastasis and oncogenic signaling had disappointing results. ${ }^{6}$ Therefore, targeting factors mediating survival after DNA damage in cancer but not normal cells are highly relevant.

Radiation (XRT) and chemotherapy induce chromosomal DNA lesions resulting in activation of the ataxia telangiectasiamutated (ATM) and ATM-Rad3-related (ATR) protein kinases in response to double-strand DNA breaks (DSBs) and replication stress, respectively. ${ }^{7-9}$ Defects in the DNA damage response (DDR) such as ATM and p53 deletion/ mutation are common in human tumors ${ }^{10}$ and occur in up to $70 \%$ of patients with PDAC. ${ }^{1,11-13}$ They might lead to a differential response in DNA repair signaling between normal and tumor cells that could be exploited to increase killing of cancer cells with DNA-damaging agents without increasing normal cell toxicity. ${ }^{7,14}$ Defects in one component of the DDR may result in tumor cells relying on the remaining intact DDR pathways, such as ATR, for survival upon DNA damage. ${ }^{15-22}$ Additionally, oncogenic mutations that often occur in human malignancies induce replication stress that can create a selective sensitivity to inhibition of ATR in cancer cells. ${ }^{18,23-25}$ Finally, hypoxia may further drive dependence on ATR in tumors. ${ }^{26}$ Thus, targeting ATR could markedly potentiate the efficacy of DNA-damaging agents without harming normal tissues.

Despite the great potential of ATR inhibitors, there is a paucity of potent, selective candidate pharmaceuticals due to of the difficulties in obtaining active ATR protein to support drug discovery efforts. We have recently described the in vitro biological profile of a highly selective ATR inhibitor (ATRi), VE$821 ;^{15,27,28}$ in the present work, we present in vitro and in vivo data for VE-822, a close analog of VE-821 with a marked increase in potency against ATR and good pharmacokinetic (PK) properties. ${ }^{29,30}$ With VE-822, we demonstrate that ATRi can profoundly sensitize tumors, both in vitro and in vivo, to

\footnotetext{
${ }^{1}$ Gray Institute for Radiation Oncology and Biology, Oxford University, Oxford, UK and ${ }^{2}$ Vertex Pharmaceuticals (Europe) Ltd, Abingdon, Oxfordshire, UK *Corresponding author: TB Brunner, Gray Institute of Radiation Oncology and Biology, University of Oxford, Old Road Campus Research Building, Roosevelt Drive, Headington, Oxford OX3 7DQ, UK. Tel: + 441865 225847; Fax: + 441865 857127; E-mail: tbbrunner@gmail.com

${ }^{3}$ Current address: Department of Radiation Therapy and Oncology, Johann Wolfgang Goethe University, Frankfurt, Germany

${ }^{4}$ These authors contributed equally to this work.

${ }^{5}$ Current address: Department of Radiotherapy and Radiation Oncology, Freiburg University, Freiburg, Germany

Keywords: ATR; novel inhibitor; radiosensitiser; pancreatic cancer; tumor selectivity

Abbreviations: PDAC, pancreatic ductal adenocarcinoma; XRT, radiation; ATM, ataxia telangiectasia-mutated; ATR, ATM-Rad3-related; ATRi, ATR inhibition; PK, pharmacokinetic; HDMECs, human dermal microvascular endothelial cells; DSB, double-strand breaks; HRR, homologous recombination repair

Received 18.7.12; revised 29.9.12; accepted 04.10.12; Edited by RA Knight
} 
radiation and radiochemotherapy with no evidence for potentiation of radiation-induced normal tissue damage.

\section{Results}

VE-822 inhibits Chk1 phosphorylation and sensitizes pancreatic cancer cells to XRT and gemcitabine in vitro. We recently described a highly selective ATRi, VE-821. ${ }^{15}$ VE-822, a close analog of VE-821, has increased potency against ATR retaining the excellent ATR selectivity profile. ${ }^{29}$ Furthermore, VE-822 has absorption, distribution, metabolism and excretion properties that support in vivo studies. Particularly, VE-822 has >100-fold cellular ATR-selectivity over the closely related phosphatidylinositol 3-kinase-related kinases ATM/DNA-PK (Table 1, Supplementary Table S1).

As ATR is the major kinase phosphorylating Chk1, we used reduction of Chk1 phosphorylation as a marker for ATRi. VE-822 (80 nM) reduced phospho-Ser345-Chk1 after gemcitabine (100 nM), XRT (6 Gy) or both in PDAC (Figure 1a). Additionally, VE-822 did not inhibit ATM, Chk2 or DNA-PK phosphorylation in response to radiation, which further supports the selectivity of VE-822 for ATR (Supplementary Figure S1). VE-822 decreased survival of irradiated PDAC (all lines used are p53-mutant; K-Ras mutant) ${ }^{31}$ (Figure 1b). Knock down of Chk1 by siRNA sensitized PSN-1 and MiaPaCa-2 cells to radiation but the radiosensitising effect was less profound compared with VE-822 (Supplementary Figure S2). Adding VE-822 to gemcitabine reduced survival 2-3-fold (Figure 1c) and dramatically more after chemoradiotherapy (Figure 1d).

VE-822 does not increase normal cell radiosensitivity and chemosensitivity in vitro. In HFL-1 normal fibroblasts, VE-822 reduced phospho-Ser345-Chk1 after gemcitabine, XRT or chemoradiotherapy (Figure 2a). However, VE-822 did not alter clonogenic survival of fibroblasts (HFL-1, MRC5; Figures $2 b$ and c). Additionally, VE-822 did not modify tube formation by human dermal microvascular endothelial cells (HDMECs) after XRT or gemcitabine (Figure 2d). These data underline the tumor specificity of VE-822-enhanced cytotoxicity of XRT and gemcitabine.

VE-822 enhances residual DNA damage in vitro. VE-822 increased XRT-induced residual $\gamma \mathrm{H} 2 \mathrm{AX}$ and 53BP1 foci compared with XRT (Figures $3 a$ and b). VE-822 pretreatment decreased Rad51 foci after XRT (Figure 3c). VE-822 alone had no effect on $\gamma \mathrm{H} 2 \mathrm{AX}$, 53BP1 or Rad51 foci

Table 1 Cellular selectivity of VE-822 for ATR over the closely related PIKKs ATM and DNA-PK

\begin{tabular}{lcc}
\hline & \multicolumn{2}{c}{ VE-822 } \\
\cline { 2 - 3 } Kinase & Ki $(\mu \mathrm{M})$ & Cell IC50 $(\mu \mathrm{M})$ \\
\hline ATR & $<0.0002$ & 0.019 \\
ATM & 0.034 & 2.6 \\
DNA-PK & $>4$ & 18.1 \\
mTOR & $>1$ & - \\
PI3K $\gamma$ & 0.22 & - \\
\hline
\end{tabular}

(data not shown). This is consistent with homologous recombination repair (HRR) inhibition causing unrepaired DNA damage.

VE-822 disrupts DNA damage-induced cell-cycle checkpoints in vitro. VE-822 alone increased the G1-phase-fraction (Supplementary Figures S3A-D). XRT enriched G2/M-phase-fraction, and this was abrogated by co-treatment with VE-822. By contrast, gemcitabine-induced S-phase arrest that was not affected by VE-822.

VE-822 increases XRT- and gemcitabine-induced apoptosis in vitro. We analyzed apoptosis in PSN-1 cells by Annexin V-FITC/PI to differentiate necrotic from early apoptotic cells (Supplementary Figure S4). VE-822 had little effect, whereas XRT and gemcitabine increased apoptosis slightly in PSN-1 while combinations of VE-822, XRT and/or gemcitabine enhanced early and late apoptosis that was strongest in the triple combination.

Efficacy of VE-822 combined with radiotherapy in xenografts. We first investigated whether VE-822 efficiently blocks phosphorylation of the main downstream target of ATR, Chk1, in tumor xenografts, in response to DNA damage. For that purpose, PSN-1 xenografts were treated with VE-822 (60 mk/kg; d0, 1), gemcitabine (100 mg/kg; d0) and/or XRT (6Gy; d1), as described in Materials and Methods. Tumors were then harvested $2 \mathrm{~h}$ post-XRT. In keeping with our in vitro observations, VE-822 inhibited phospho-Ser-345-Chk1 in xenografts after DNA-damaging agents (Figure 4a), establishing VE-822 as a potent inhibitor of ATR in vivo.

We then asked whether mice bearing PSN-1 xenografts would show a better response to radiotherapy when co-treated with VE-822 (Growth delay experiment I; Figures $4 \mathrm{~b}$ and $\mathrm{c}$ ). Subscripts in the text indicate day of treatment. The time for tumors to grow to $600 \mathrm{~mm}^{3}$ (TV600) in the $\mathrm{XRT}_{1}$ group was significantly longer than in the vehicle or VE-822 $0-5$ $(P<0.001)$ treated groups. Although VE-822 alone had no effect on tumor growth at the dose used in this study, administration of XRT plus VE-822 for either 6 days $\left(\mathrm{VE}-822_{0-5} \mathrm{XRT}_{1}\right)$ or 4 days $\left(\mathrm{VE}-822_{0-3} \mathrm{XRT}_{1}\right)$ more than doubled the TV600 of XRT alone $(P<0.001)$. Interestingly, the TV600 for the VE-822 ${ }_{0-5} \mathrm{XRT}_{1}$ group was significantly longer than the VE-822 $2_{0-3} \mathrm{XRT}_{1}$ group $(P<0.001)$. No body weight loss was detected in any of the animals in this study (Supplementary Figure S4A). Taken together, these data demonstrate the marked radiosensitising potential of VE-822.

Clinically, radiation is typically delivered in fractions of approximately $2 \mathrm{~Gy}$ in PDAC. Therefore, we delivered fractionated radiation in five daily fractions of 2 Gy $\left(X R T_{1-5}\right)$ to PSN-1 tumors (Growth delay experiment II; Figures 4d and e). Radiation alone $\left(\mathrm{XRT}_{1-5}\right)$ significantly delayed tumor growth compared with tumors treated with vehicle $(P<0.001)$. Combination of VE-822 and radiation (VE-822 ${ }_{0-5} \mathrm{XRT}_{1-5}$ ) again significantly delayed regrowth compared with $\mathrm{XRT}_{1-5}(P<0.001)$, and no effects on body weight were observed (Supplementary Figure S5b).

We next tested the efficacy of VE-822 in a different tumor xenograft, MiaPaCa-2 (Growth delay experiment III; 
a
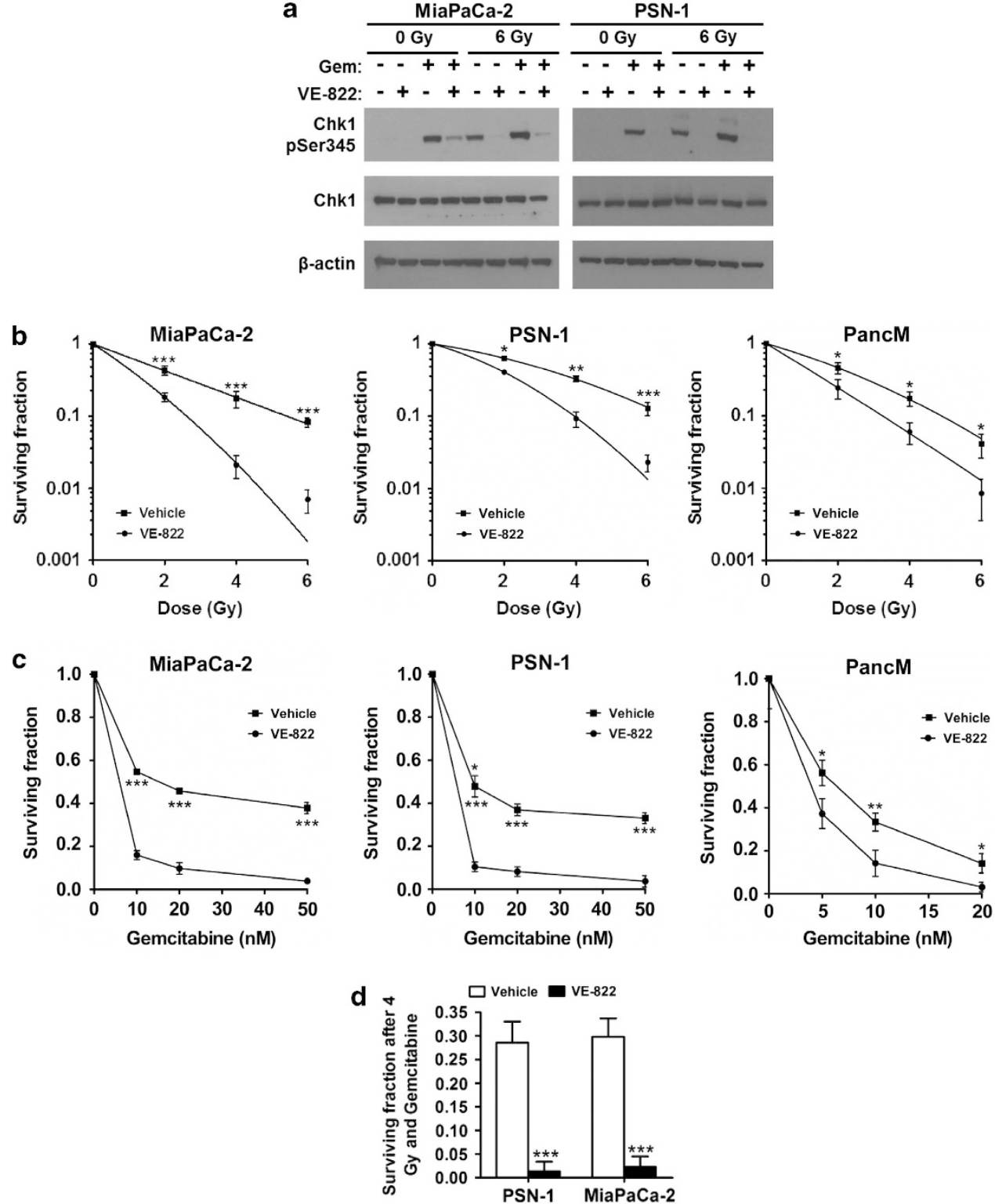

Figure 1 VE-822 attenuates ATR signaling pathway and reduces survival in tumor cells in response to XRT and gemcitabine. (a) Chemical structure of VE-821. (b) Immunoblot for Chk1 phosphorylation (Ser 345) in lysates from cells obtained $2 \mathrm{~h}$ after XRT (6 Gy) or $4 \mathrm{~h}$ after gemcitabine. Treatment with VE-822 (80 nmol//) was initiated either $2 \mathrm{~h}$ before XRT or $1 \mathrm{~h}$ after gemcitabine. Blots were also stained with $\beta$-actin and total Chk1, as indicated. (c) Clonogenic survival of cells after exposure to VE-822 $(80 \mathrm{nM})$ for $1 \mathrm{~h}$ before until $18 \mathrm{~h}$ post-XRT. (d) Clonogenic survival of cells exposed to gemcitabine for $24 \mathrm{~h}$ before addition of $80 \mathrm{nM}$ VE- 822 for another $18 \mathrm{~h}$. Gemcitabine was removed immediately before addition of VE-822. (e) Clonogenic survival in response to the triple combination. Cells were pretreated with $10 \mathrm{nM}$ and $5 \mathrm{nM}$ of gemcitabine, respectively, for $24 \mathrm{~h}$. Gemcitabine was washed away, VE-822 ( $80 \mathrm{nM}$ ) was added for $1 \mathrm{~h}$ before until $18 \mathrm{~h}$ after XRT with 4 Gy (means \pm S.D.; $n=3$ ). ${ }^{*} P<0.05 ;{ }^{* \star} P<0.01$; ${ }^{* * *} P<0.001$

Figures $4 \mathrm{f}$ and $\mathrm{g}$ ). Administration of the ATRi alone (VE-822 $2_{0-5}$ ) at $60 \mathrm{mg} / \mathrm{kg}$ resulted in no statistical change in tumor growth, as compared with the control (Figure 4f). Radiation alone $\left(X R T_{1}\right)$ resulted in a significant tumor growth delay compared with control $(P<0.01)$. Strikingly in the combined group (VE-822 $\left.{ }_{0-5} \mathrm{XRT}_{1} ; \mathrm{n}=4\right)$ only $2 / 4$ tumors regrew. The TV600 for the two regrowing tumors was significantly longer than the TV600 for the $\mathrm{XRT}_{1}$ group $(P<0.001)$. Again, no weight loss was recorded in any of the mice (Supplementary Figure S4C).
Finally, intermittent VE-822 dosing (days 0, 2 and 4) at three different doses $(15,30$ and $60 \mathrm{mg} / \mathrm{kg}$ ) was tested for radiosensitisation, and the time for tumors to grow to $400 \mathrm{~mm}^{3}$ (TV400) was analyzed (Growth delay experiment IV; Supplementary Figures S6A and B). A clear dose-dependent radiosensitisation response to $\mathrm{VE}-822$ was observed, with $60 \mathrm{mg} / \mathrm{kg}$ the most efficacious dose (Supplementary Figures S6A and B). No weight loss was observed in any of the mice (Supplementary Figure S6C). Collectively, growth delay experiments I-IV reveal that ATRi using VE-822 can safely 

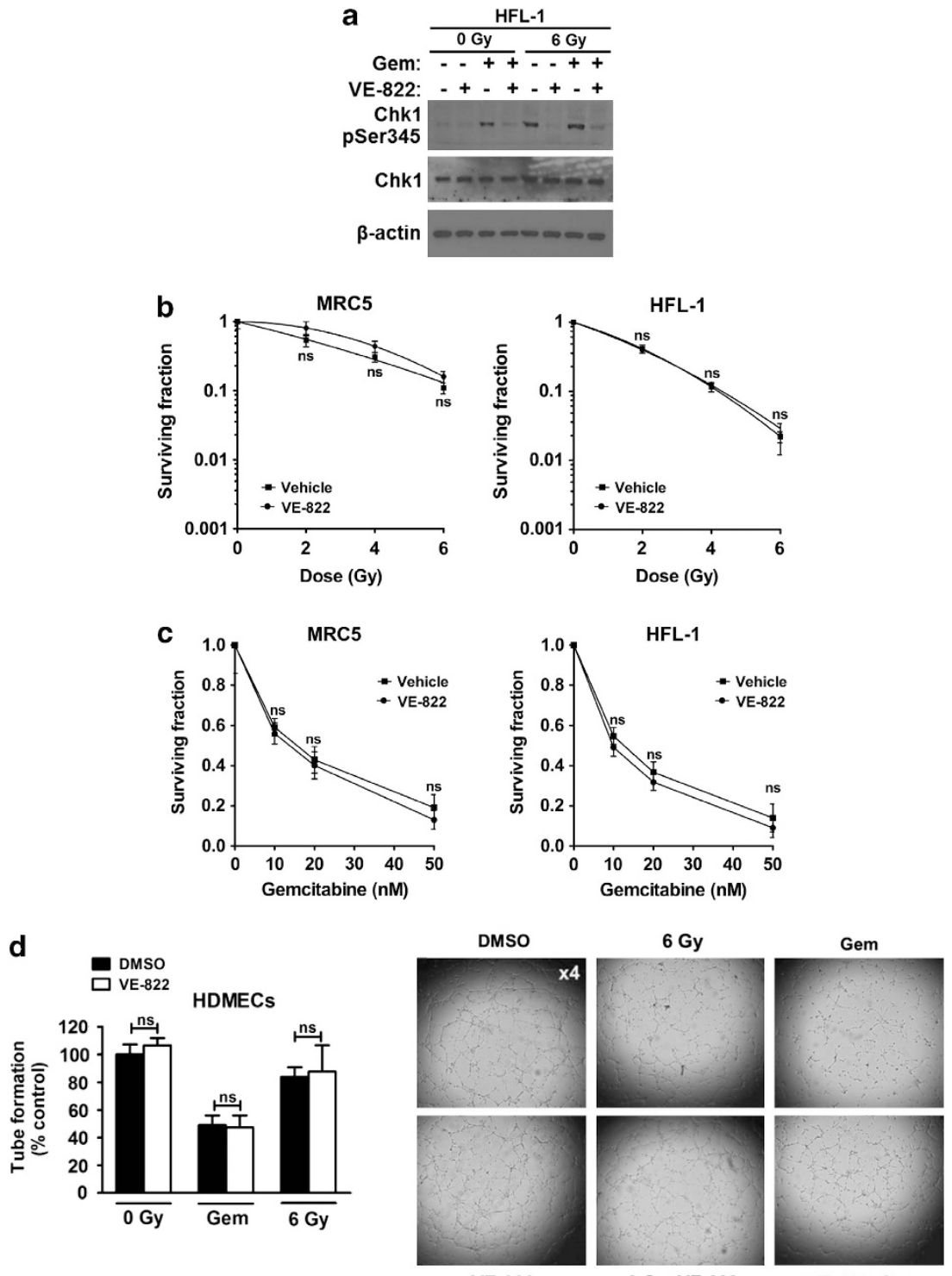

Figure 2 VE-822 attenuates ATR signaling in normal cells without enhancing radiation and gemcitabine killing in normal cells. (a) Phosphor-Chk1 (Ser 345) western blot in HFL-1 normal cells treated as tumor cells in Figure 1b. (b) Clonogenic survival of MRC5 and HFL-1 normal cells treated as tumor cells in Figure 1c. (c) Clonogenic survival of cells treated as tumor cells in Figure 1d. (d) VE-822 ( $80 \mathrm{nM}$ ) was added to HDMECs $1 \mathrm{~h}$ before XRT ( $6 \mathrm{~Gy})$ up to $8 \mathrm{~h}$ post-XRT when tube formation was analyzed. Cells were also pretreated with 50 gemcitabine $(50 \mathrm{nM})$ for $24 \mathrm{~h}$, gemcitabine was washed away, VE-822 ( $80 \mathrm{nM}$ ) was added and tube formation was assessed $9 \mathrm{~h}$ later. The number of capillary tube branches was quantified and normalized to the control group (four power fields per sample). Representative images of capillary tube formation in HDMECs are shown on the right (means \pm S.D.; $n=3$ in fibroblasts; $n=2$ in HDMECs). NS, not significant. ${ }^{*} P<0.05 ;{ }^{*} P<0.01$

and dose-dependently sensitize tumors to both single and fractionated XRT dose schedules.

\section{Efficacy of VE-822 in combination with chemoradiotherapy} in pancreatic tumor xenografts. Above, we investigated the potential of VE-822 to enhance response of PDAC xenografts to radiotherapy. As gemcitabine-based chemoradiation is frequently used in patients with PDAC, ${ }^{3,4}$ we tested gemcitabine in combination with VE-822 plus XRT (Growth delay experiment $\mathrm{V}$; Figures $5 \mathrm{a}$ and $\mathrm{b})$. Gemcitabine $(100 \mathrm{mg} / \mathrm{kg})$ was given at day $0\left(\mathrm{Gem}_{0}\right)$, XRT on d1 $\left(\mathrm{XRT}_{1}\right)$ and VE-822 $(60 \mathrm{mg} / \mathrm{kg})$ on $\mathrm{d} 1,3$ and $5\left(\mathrm{VE}-822_{1,3,5}\right)$. XRT led to a significant increase in TV400 $(P<0.05)$ compared with control. Gemo at this dose did not alter tumor growth significantly. Adding gemcitabine to VE-822 (Gemo VE-822 13,5 ) did not significantly increase TV400 compared with gemcitabine alone $(P>0.05)$ under the conditions of this experiment. Adding XRT to gemcitabine $\left(\mathrm{Gem}_{0} \mathrm{XRT}_{1}\right)$ increased tumor growth delay compared with $\operatorname{Gem}_{0}(P<0.05)$. Similarly, the tumor growth delay in the VE-822 ${ }_{1,3,5} \mathrm{XRT}_{1}$ group was significantly longer compared with the $\mathrm{XRT}_{1}$ group $(P<0.05)$. VE-822 added to the combination of gemcitabine + XRT $\left(\right.$ Gem $\left._{0} \mathrm{XRT}_{1} \mathrm{VE}-\mathrm{822}_{1,3,5}\right)$ substantially prolonged the tumor growth delay compared with the $\mathrm{Gem}_{0} \mathrm{XRT}_{1}$ group $(P<0.001)$. In addition, no weight loss was observed throughout the experiment (Figure $5 \mathrm{c}$ ). These results 
a

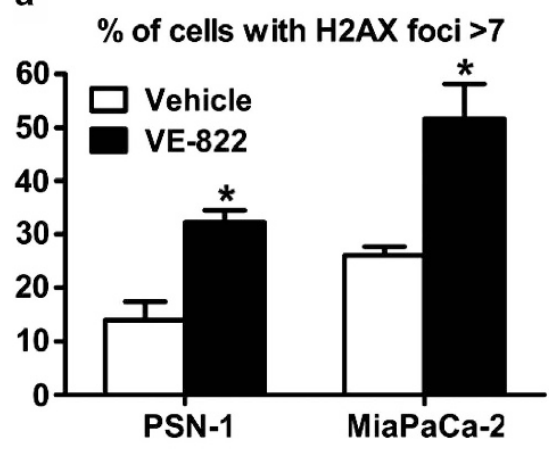

b

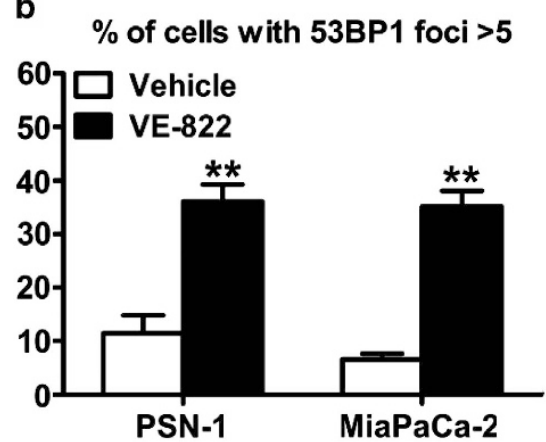

C

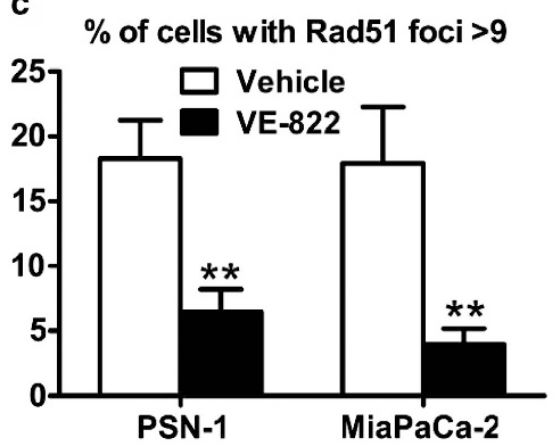

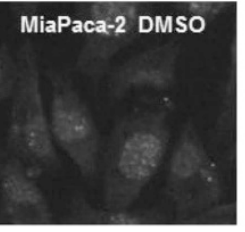
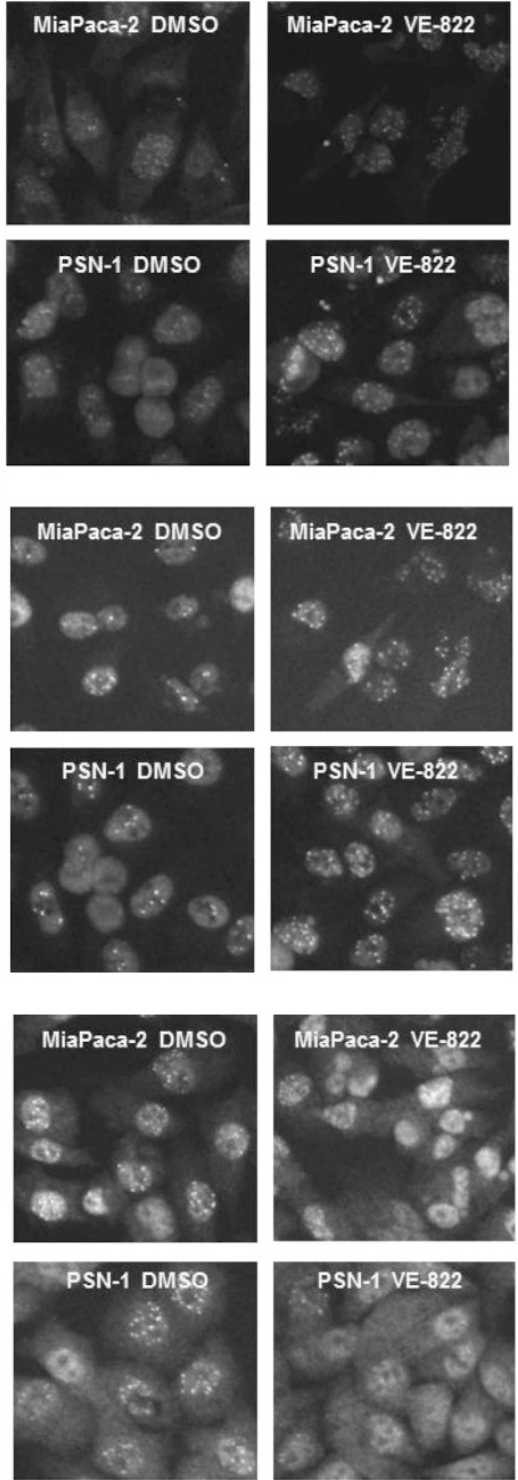

Figure 3 Effect of VE-822 on 53BP1, $\gamma \mathrm{H} 2 \mathrm{AX}$ and Rad51 foci formation. (a and $\mathbf{b}) \mathrm{VE}-822(80 \mathrm{nM}$ ) was added to cells $1 \mathrm{~h}$ before XRT with 6 Gy. Cells were fixed at $24 \mathrm{~h}$ post-XRT, stained for $\gamma \mathrm{H} 2 \mathrm{AX}$ and 53BP1 foci and the percentage of cells with more than 7 and 5 foci per cell was quantitated, respectively. (c) The percentage of cells with more than 9 Rad51 foci per cell was quantitated at $6 \mathrm{~h}$ post-XRT. Representative images are shown on the right (means \pm S.D.; $n=3$ ). ${ }^{*} P<0.05 ;{ }^{* *} P<0.01$

underscore the potential of VE-822 as a sensitizer to gemcitabine-based chemoradiation therapy for PDAC.

As the tolerance of XRT in PDAC is restricted by the small bowel, we assessed the effect of VE-822 on intestinal morphology. ${ }^{32,33}$ VE-822 combined with abdominal XRT did not significantly increase the number of TUNEL-positive apoptotic jejunal cells compared with XRT alone (Figure $5 \mathrm{~d}$ ). Furthermore, VE-822 administered with XRT did not increase villus tip loss or villi shortening when compared with XRT alone (Figures $5 \mathrm{e}$ and $\mathrm{f}$ ). In keeping with these findings, equivalent body weight loss was observed in the combination and XRT-only groups (Figure $5 \mathrm{~g}$ ). Thus, in our model, we found no evidence for enhancement of XRT-induced gastrointestinal damage by VE-822.
Effect of VE-822 on tumor vessel density and proliferation. We used CD31 immunostaining to assess the effect of VE-822 on tumor angiogenesis (Supplementary Figure S7). In growth delay experiments I-III, VE-822 therapy, alone or with XRT, did not alter vessel density (Supplementary Figures S7A and B). In growth delay experiment $\mathrm{V}$, a significantly reduced vessel density was observed after therapy with gemcitabine, whereas addition of VE-822 and/or XRT to gemcitabine did not alter vessel density significantly. There was no significant difference in the proportion of Ki67-positive cells following any combination of agents, indicating that proliferation had not been affected (Supplementary Figures S8A-D). 


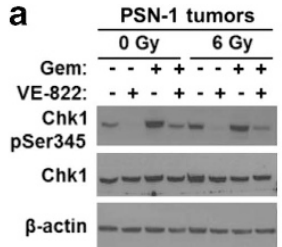

b

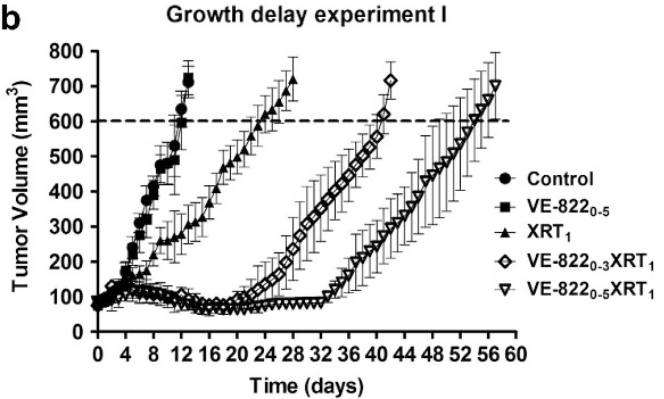

d

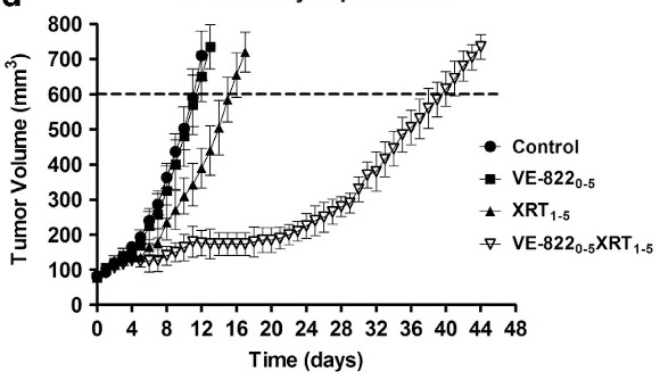

f

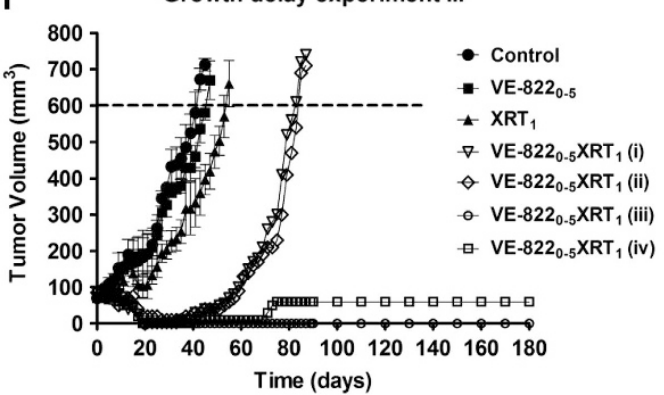

C

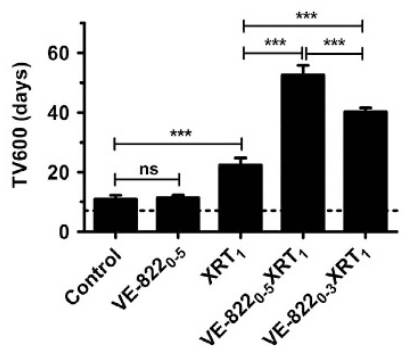

e

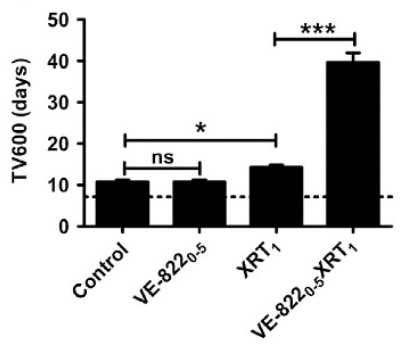

g

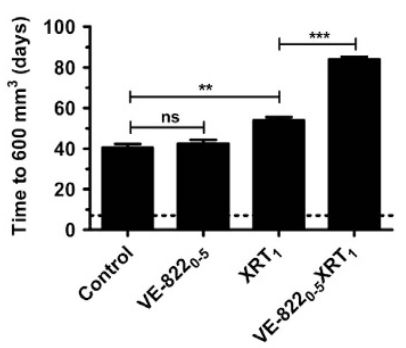

Figure 4 VE-822 enhances the therapeutic efficacy of radiation (XRT) in MiaPaCa-2 and PSN-1 xenograft models. (a) Mice bearing PSN-1 tumors (volume $\sim 300 \mathrm{~mm}^{3}$ ) were treated with VE-822 (60 mg/kg; days 0 and 1) and/or gemcitabine (100 mg/kg; day 0) and/or XRT (6 Gy; day 1). Tumors were harvested $2 \mathrm{~h}$ post-XRT. Chk1 phosphorylation (Ser345) was examined by immunoblot in tumor homogenates. Blots were also stained with $\beta$-actin and total Chk1, as indicated. (b) When tumors reached a volume of $\sim 80 \mathrm{~mm}^{3}$, designated as day 0 , mice were treated as indicated. Growth delay experiment I: mice bearing PSN-1 tumors $(n=4-5)$ were treated daily with either vehicle (control), VE-822 (60 mg/kg) from days 0 to 5 (VE-822 $\left.2_{-5}\right), 6$ Gy at day $1\left(\mathrm{XRT}_{1}\right)$ or VE-822 plus 6 Gy by administering the drug for either 4 days (VE-8220-3XRT ${ }_{1}$ ) or 6 days $\left(\right.$ VE-822 $-5 \mathrm{XRT}_{1}$ ). (c) Time in days, from day 0 , to reach a tumor volume of $600 \mathrm{~mm}^{3}$ (TV600) in the different groups. (d) Growth delay experiment II: mice bearing PSN-1 tumors $(n=4)$ were treated with vehicle (control), VE-822 from days 0 to $5\left(\mathrm{VE}-822_{0-5}\right)$, fractionated XRT using five daily doses of 2 Gy from day 1 to day 5 (XRT ${ }_{1-5}$ ) or the combination of VE-822 + fractionated XRT (VE-822 ${ }_{0-5} \mathrm{XRT}_{1-5}$ ). (e) Time from day 0 to TV600 in the different groups. (f) Growth delay experiment III: mice bearing MiaPaCa-2 xenograft tumors $(n=4)$ were treated as in $(\mathbf{b})$ with the difference that only one VE-822 + XRT combination was tested (VE-822 $\left.{ }_{0-5} \mathrm{XRT}_{1}\right)$. The volumes of tumors in the combined VE-822 + XRT group are plotted individually [VE-822 ${ }_{0-5} \mathrm{XRT}_{1}$ (i, ii, iii and iv)]. (g) Time in days, from day 0, to TV600 in the different groups. Of note, the TV600 in the VE-822 ${ }_{0-5} \mathrm{XRT}_{1}$ group was estimated based only on the two tumors with re-growth (VE-822 ${ }_{0-5} \mathrm{XRT}$ (i) and (ii)). The growth curves were plotted until mice were killed. In (b, $\mathbf{d}$ and $\mathbf{f}$ ), points show the mean of tumor volume $\left(\mathrm{mm}^{3}\right)$ of each treatment group $(n=4-5)$. Notably, in the growth delay experiment III (f), harvesting of the VE-822 ${ }_{0-5} \mathrm{XRT}_{1}$ (iv) tumor revealed a cystic mass filled with fluid and necrotic debris (means \pm S.D.). ns, not significant; ${ }^{*} P<0.05 ;{ }^{* *} P<0.001$

In vivo imaging of DNA DSBs following radiation and VE-822. In vitro, VE-822 led to persistent $\gamma \mathrm{H} 2 \mathrm{AX}$ foci after XRT. To examine persistence of $\gamma \mathrm{H} 2 \mathrm{AX}$ in vivo, we used a SPECT probe, which we have recently developed, that binds to phosphorylated $\gamma \mathrm{H} 2 \mathrm{AX} .{ }^{34}$ We have shown that anti- $\gamma \mathrm{H} 2 \mathrm{AX}$ antibody, coupled to the Tat peptide DTPA, allows radiolabelling with ${ }^{111}$ In and can be used for specific imaging of DNA damage in live animals. ${ }^{34}$ We performed SPECT/CT at $24 \mathrm{~h}$ post-XRT to non-invasively image DNA damage, as induced by XRT (6 Gy; day 1). We administered VE-822 
a

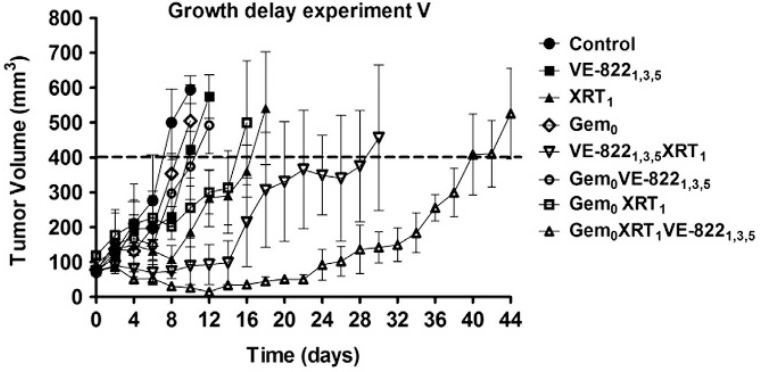

b

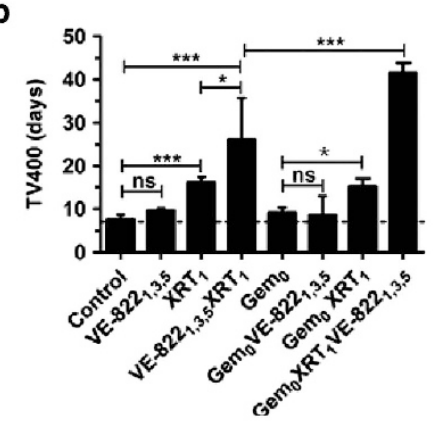

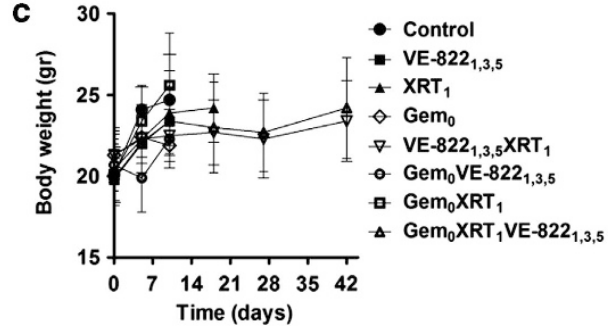

d
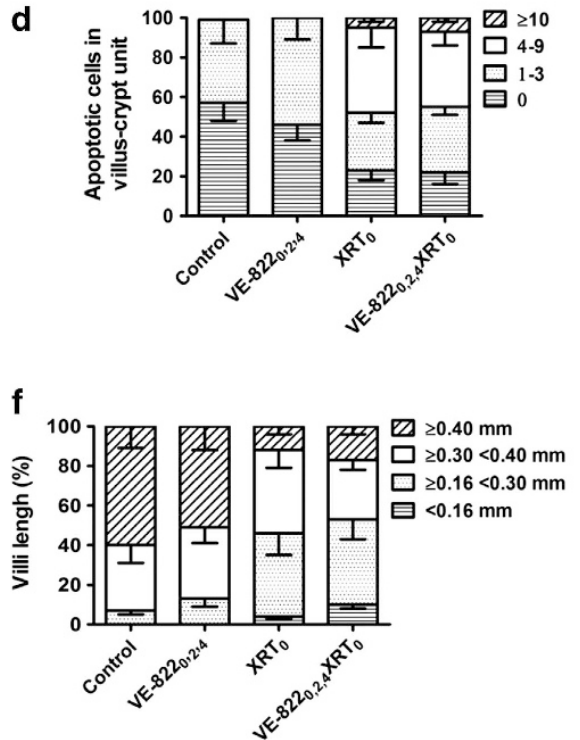

e
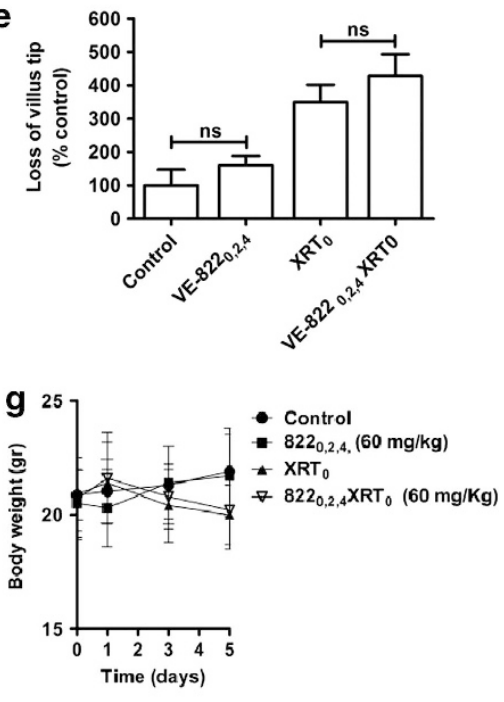

Figure 5 VE-822 enhances tumor response in combination with XRT and gemcitabine in PSN-1 xenografts. (a) Growth delay experiment V: when tumors reached a volume of $\sim 80 \mathrm{~mm}^{3}$, treatment with VE-822 $(60 \mathrm{mg} / \mathrm{Kg})$, XRT (6 Gy) and/or gemcitabine $(100 \mathrm{mg} / \mathrm{Kg})$ was started. Subscripts in the text indicate day of treatment. Mean of tumor volume $\left(\mathrm{mm}^{3}\right)$ of each treatment group $(n=4-5)$; bars, S.D. (b) the average time (days) for tumors to reach a volume of $400 \mathrm{~mm}^{3}$ (TV400) from day 0 is shown for the different groups (means \pm S.D.). ns, not significant; ${ }^{*} P<0.05$; ${ }^{* *} P<0.01$; ${ }^{* *} P<0.001$. (c) weight of mice throughout the experiment. (d) VE-822 does not increase normal intestinal cell radiosensitivity in vivo. Mice $(n=3)$ were treated with VE-822 $(60 \mathrm{mg} / \mathrm{kg})$ at days 0,2 , and 4 and/or abdominal XRT (6 Gy; day 0$)$, as indicated in the subscripts. VE-822 was administered $2 \mathrm{~h}$ before XRT. At day 5 mice were killed, and pieces of proximal jejunum were removed and fixed in $3 \%$ formalin/PBS for histological examinations. Frequency histogram of apoptotic cells per villus-crypt unit, based on TUNEL staining. (e and f) villus tip loss and villi length in the different groups. Data are means from six sections each obtained from different mice. Approximately 100 crypt-villus units were scored per group. (g) weight in mice treated as indicated (means \pm S.D.). ns, not significant; ${ }^{*} P<0.05$

$(60 \mathrm{mg} / \mathrm{Kg})$ on days 0 and 1 . Representative images of ${ }^{111}$ In-DTPA-anti- $\gamma \mathrm{H} 2 \mathrm{AX}-\mathrm{Tat}$ uptake in PSN-1 tumor xenografts are shown in Supplementary Figure S9A. In mice bearing PSN-1 xenografts, tumor uptake of ${ }^{111}$ In-DTPA-anti$\gamma \mathrm{H} 2 \mathrm{AX}$-Tat was 2.5 times higher in $\mathrm{XRT}_{1}$ mice $(P<0.05)$ than in unirradiated mice. Although no elevation in uptake was detected in tumors treated with VE-822 alone, uptake in tumors exposed to VE-822 plus XRT (VE-822 ${ }_{0,1} \mathrm{XRT}_{1}$ ) was $44 \%$ higher compared with $\mathrm{XRT}_{1}(P<0.05$; Supplementary Figure S9B), suggesting that addition of VE-822 increased $\gamma \mathrm{H} 2 \mathrm{AX}$ phosphorylation and persistence of DNA damage caused by XRT. These results mirror our analysis of $\gamma \mathrm{H} 2 \mathrm{AX}$ foci in vitro and are consistent with the disruption of DSB repair in vivo by VE-822. 


\section{Discussion}

In the present study, we investigated the potential of VE-822, a potent ATRi, to sensitize PDAC cells and xenografts to XRT and gemcitabine. ATRi by VE-822 resulted in profound sensitization of PDAC cells to radiotherapy both in vitro and in xenografts, to the extent that the combination of VE-822 and XRT prevented MiaPaCa-2 tumor regrowth in some mice. VE-822 is a close analog of the previously reported selective ATRi, VE-821 with excellent potency against ATR (Ki 200pM) and $>100$-fold cellular selectivity for ATR over ATM and DNA-PK (Table 1, Supplementary Table S1). The selectivity of VE-822 for ATR is also supported by the lack of inhibition of DNA-PK, ATM or Chk2 protein phosphorylation by VE-822 after irradiation of PDAC cells. VE-822 blocked XRT and gemcitabine-induced Chk1 Ser345 phosphorylation in PDAC cells and tumors, as well as in normal cell fibroblasts, confirming its ability to disrupt ATR signaling. Of most relevance to the clinical setting, VE-822 sensitized tumors to fractionated XRT. In addition to sensitizing tumors to XRT, VE-822 profoundly sensitized tumors to gemcitabine-based chemoradiation. Here, VE-822 remained effective even with doses of gemcitabine that alone had no effect on tumor growth. In accordance to previous reports, ${ }^{35-37}$ addition of VE-822 to XRT and/or gemcitabine resulted in increased early and late apoptosis in PDAC cell cultures.

Previous work has shown that HRR-deficient cells are more radiosensitive compared with HRR-proficient cells, ${ }^{38}$ although enhancing HRR by overexpression of Rad51, a major mediator of HRR, is associated with resistance to radiation. ${ }^{39}$ VE-822 decreased Rad51 foci in irradiated tumor cells, showing that VE-822-mediated radiosensitivity was associated with inhibition of HRR. Furthermore, VE-822 caused increased persistence of residual $\gamma \mathrm{H} 2 \mathrm{AX}$ expression after XRT both in PDAC cells and tumor xenografts. By promoting a strong S-phase arrest, the addition of gemcitabine to XRT may further enhance dependence on ATR-mediated HRR for DSB repair and cancer cell survival. This model would be consistent with the dramatic anticancer effects we observed for the triple combination of VE-822, XRT and gemcitabine in vivo. VE-822 additionally led to abrogation of the XRTinduced G2 checkpoint in vitro, which could also contribute to the radiosensitization effect.

VE-822 did not sensitize normal cells to XRT or gemcitabine, despite inhibiting XRT- or gemcitabine-induced Chk1 phosphorylation, similarly to the findings with VE-821 in vitro ${ }^{15}$ and was well tolerated from animals. Furthermore, as damage to the small intestine is commonly dose-limiting during radiotherapy for PDAC, ${ }^{5,40}$ we specifically quantified the effect of VE-822 on bowel radiosensitivity. Notably, addition of VE-822 to XRT did not further enhance the jejunal apoptosis or villus damage observed with XRT alone, in agreement with a recent study showing that ATR suppression minimally affects normal tissue homeostasis. ${ }^{41}$ Collectively, these data indicate that ATRi by VE-822 is not cytotoxic to normal tissue and, furthermore, we failed to find any evidence of enhanced gastrointestinal epithelial tract damage associated with XRT.

Approximately $50-70 \%$ of PDAC harbor mutations in ATM and p53-mediated signaling. ${ }^{1,11}$ ATR depletion can strongly enhance DNA damage-induced tumor cell killing and suggest that the frequent loss of ATM-p53 signaling may be an important determinant of this finding. ${ }^{15,42-44}$ Moreover, prolonged disruption of the ATR pathway can exacerbate the levels of replication stress in oncogene-driven murine tumors to promote cell killing. ${ }^{18,23-25}$ These observations provide an explanation for the tumor selective effects of ATRi by VE-822.

PDAC is an incurable disease and survival remains poor. ${ }^{1,2}$ Gemcitabine-based radiochemotherapy can increase local control rates and improve progression-free survival but is associated with normal tissue toxicity, which limits its therapeutic utility. 5,40 Our data show that VE-822 can dramatically sensitize PDAC cancer cells to radiochemotherapy both in vitro and in vivo. Thus ATRi, and specifically VE-822, represents a very promising candidate for combination with radiation and gemcitabine.

\section{Conclusion}

In the present work, we demonstrate that ATRi by VE-822 profoundly radiosensitizes PDAC cells and xenografts and increases the growth delay induced by XRT combined with gemcitabine in PDAC xenografts. VE-822 did not enhance toxicity to normal cells and tissues. The tumor selectivity shown by VE-822 provides strong evidence that ATRi represents a promising new approach to markedly increase the efficacy of the current therapies for PDAC.

\section{Materials and Methods}

Cell culture. MiaPaCa-2 PDAC cell lines were obtained from American Type Culture Collection (CRL-1420). PSN-1 PDAC cells were obtained from Merck \& Co, Inc. (Rahway, NJ, USA) ${ }^{45}$ Tumor cells, normal human fibroblast cells (MRC5: CCL-171; and HFL-1: CCL-153) and the primary PDAC line (PancM; passage 17) were obtained and cultured as previously described. ${ }^{15,31,46}$ HDMECs (Lonza, Slough, UK) were cultured as reported. ${ }^{47}$

ATR inhibitor preparation and treatment. The ATRis, VE-821 and VE-822, were obtained from Vertex Pharmaceuticals (Europe) Ltd (Abingdon, UK) in solution in dimethyl sulfoxide for in vitro studies. Vehicle controls were equal volumes of the same concentration of dimethyl sulfoxide. For the in vivo studies, VE-822 was dissolved in 10\% Vitamin E d-alpha tocopheryl polyethylene glycol 1000 succinate and administered by gavage, in $200 \mu \mathrm{l}$.

Biochemical and cellular inhibition of ATR and related kinases. Broad kinase selectivity profiling and analysis of biochemical and cellular inhibition of ATR and related kinases were assessed as previously described. ${ }^{15}$

Immunoblotting. Cells were treated with VE-822 ( $80 \mathrm{nM})$ and/or gemcitabine $(20 \mathrm{nM})$ for $1 \mathrm{~h}$ before XRT (6Gy). After rinsing with cold PBS, lysates were obtained at $2 \mathrm{~h}$ post-XRT using reducing Triton lysis buffer. Tumor lysates were obtained from female Balb/c nude mice bearing PSN-1 xenografts (volume $\sim 300$ $\left.\mathrm{mm}^{3}\right)$ treated with VE-822 $(60 \mathrm{mg} / \mathrm{kg}$; days 0 and 1) and/or gemcitabine $(100 \mathrm{mg} /$ $\mathrm{kg}$; day 0 ) and/or XRT (6 Gy; day 1). Gemcitabine (day 0) was administered $24 \mathrm{~h}$ before XRT. VE-822 was administered $2 \mathrm{~h}$ after gemcitabine (day 0 ) and $2 \mathrm{~h}$ before XRT (day 1). Tumors were harvested $2 \mathrm{~h}$ post-XRT, snap frozen, homogenized and prepared in the same buffer used in cells. Immunoblotting was performed as described. ${ }^{46}$ Proteins were detected using antibodies to phosphoChk1 Ser345, phospho-Chk2 T68, total Chk2 (Cell Signalling, Hitchin, UK), total Chk1 (New England Biolabs, Hitchin, UK), phospho-ATM S1981 (Epitomics, Inc, Burlingame, CA, USA), total ATM (Epitomics, Inc.), DNA-PKcs phospho Ser2056 (Abcam, Cambridge, UK), total DNA-PK (BD Pharmigen, Oxford, UK) at (1:1000 dilution) and $\beta$-actin clone AC-15 (Sigma, Gillingham, UK; $1: 4000$ dilution). Cells were irradiated as described before. ${ }^{46}$ 
Clonogenic survival assay. VE- $822(80 \mathrm{nM})$ was administered $1 \mathrm{~h}$ before $\mathrm{XRT}$ and was washed away $17 \mathrm{~h}$ after XRT. For chemotherapy, cells were exposed to gemcitabine $(10,20$ or $50 \mathrm{nM})$ for $24 \mathrm{~h}$ before addition of VE-822 $(80 \mathrm{nM})$ for another $18 \mathrm{~h}$. Gemcitabine was washed away immediately before addition of VE-822. The clonogenic survival of cells was assessed as reported. ${ }^{46}$

Knock down of Chk1 by siRNA. Cells were transfected using either Chk1 siRNA carried out with the following sequence $\left(5^{\prime}-3^{\prime}\right)$ : GGCUUGGCAACAGUAUU UCGGUAUA or with stealth RNAi negative control (Invitrogen, Paisley, UK). In total, $2 \times 10^{5}$ MiaPaca-2 cells or $2.5 \times 10^{5}$ PSN-1 cells were seeded per well $24 \mathrm{~h}$ before transfection. Two reaction mixtures were set up per transfection. Mixture 1 contained $3.125 \mu \mathrm{l}$ of $20 \mu \mathrm{M}$ siRNA, $121.875 \mu \mathrm{l}$ diethylpyrocarbonate water and $125 \mu \mathrm{l}$ of Dulbecco's Modified Eagle Medium (DMEM; serum-free) per well. Mixture 2 contained $5 \mu \mathrm{l}$ Dharmafect transfection reagent and $245 \mu \mathrm{l}$ DMEM (serum-free) per well. Each mixture was incubated for $5 \mathrm{~min}$ at room temperature, then combined and left to incubate for a further $20 \mathrm{~min}$ at room temperature. The final reaction mixture $(500 \mu l)$ for each well was then diluted by adding $2 \mathrm{ml}$ DMEM plus FBS. The old media was aspirated from cells and $2 \mathrm{ml}$ of the transfection mixture was added. Twenty-four hours post-transfection, the old media was aspirated from cells and $2 \mathrm{ml}$ of fresh DMEM plus FBS media was added. Finally, cells were harvested and processed for immunobloting blotting (for total Chk1 and $\beta$-actin, as described above) or processed for clonogenic assay (as described above) after incubation at $37^{\circ} \mathrm{C}$ for $48 \mathrm{~h}$.

Immunohistochemical analysis of $\gamma \mathrm{H} 2 \mathrm{AX}$, 53BP1 and Rad51 foci. VE-822 ( $80 \mathrm{nM})$ was added $1 \mathrm{~h}$ before XRT (6 Gy). The residual DNA damage was assessed by 53BP1 and $\gamma \mathrm{H} 2 \mathrm{AX}$ in PSN-1 and MiaPaCa-2 cells at $24 \mathrm{~h}$ post-XRT with 6 Gy. HRR was analyzed by Rad51 focus formation at $6 \mathrm{~h}$ post-XRT. The analysis for residual $\gamma \mathrm{H} 2 \mathrm{AX}, 53 \mathrm{BP} 1$ and Rad51 foci was as described. ${ }^{46}$

Cell-cycle assay. Cells were treated with VE-822 $(80 \mathrm{nM})$ for $1 \mathrm{~h}$ before XRT (6 Gy) until cells were harvested. Gemcitabine ( $10 \mathrm{nM})$ was added for $24 \mathrm{~h}$ pre-XRT and was removed before addition of VE-822. Cell-cycle distribution was investigated at $12 \mathrm{~h}$ and $24 \mathrm{~h}$ after XRT as described elsewhere. ${ }^{46,47}$ Data represent three independent experiments.

Apoptosis in vitro assay. Gemcitabine $(10 \mathrm{nM})$ was added $24 \mathrm{~h}$ pre-XRT and was replaced with fresh medium before addition of VE-822. PSN-1 cells were treated with VE-822 ( $80 \mathrm{nM})$ for $1 \mathrm{~h}$ before, through to $18 \mathrm{~h}$ after, XRT (6 Gy). Apoptosis was analyzed $48 \mathrm{~h}$ after XRT by flow cytometry using an Annexin V-FITC kit with $\mathrm{PI}^{47}$

Capillary tube formation. HDMECs were exposed to VE-822 ( $80 \mathrm{nM})$ for $1 \mathrm{~h}$ pre-XRT (6 Gy). Cells were trypsinized immediately after XRT, plated onto 24-well plates that was previously coated with Matrigel $(300 \mu \mathrm{L}$ per well; BD Biosciences, Oxford, UK) and tube formation was analyzed $8 \mathrm{~h}$ post-XRT. HDMECs were also pretreated with $50 \mathrm{nM}$ gemcitabine for $24 \mathrm{~h}$, gemcitabine was washed away, $80 \mathrm{nM}$ VE-822 was added and tube formation was assessed $9 \mathrm{~h}$ later. Tube formation was analyzed as described. ${ }^{47}$

Xenograft studies. Animal experiments involving mice were performed according to the limits and guidelines of University of Oxford and the Home Office, UK. ${ }^{48}$ MiaPaCa-2 cells and PSN- 1 cells $\left(10^{6}\right.$ in $50 \mu$ l serum-free medium mixed with $50 \mu$ l of Matrigel) were inoculated subcutaneously in female Balb/c nude mice (Harlan, Wolverhampton, UK). When the xenograft tumors reached $\sim 80 \mathrm{~mm}^{3}$, the mice were randomized. Tumor xenografts were irradiated and volumes were measured as we recently described. ${ }^{49}$

VE-822 $(60 \mathrm{mg} / \mathrm{kg})$ was administered by oral gavage on one of three alternate schedules; either daily on days $0-5$ (total of six days dosing), daily on days 0 through to 3 (total of 4 days dosing) or on days 1,3 and 5 . XRT ( 6 Gy) was given either on days 0 or 1 or days 1-5 (total of 5 days dosing; 2 Gy). Gemcitabine was dosed at $100 \mathrm{mg} / \mathrm{kg}$ by intraperitoneal injection on day 0 . XRT to the tumor was given $2 \mathrm{~h}$ after initiation of VE-822 treatment. The gemcitabine at $100 \mathrm{mg} / \mathrm{kg}$ does not itself lead to tumor growth delay (data not shown).

Immunostaining and microscopy. Tumors were harvested, snap frozen and stored in $-80^{\circ} \mathrm{C}$. In all, $10-\mu \mathrm{m}$ sections were pretreated with $0.3 \%$ hydrogen peroxide in PBS for $20 \mathrm{~min}$, followed by TNB blocking buffer for $30 \mathrm{~min}$ and primary antibody in blocking buffer for $1 \mathrm{~h}$. Blood vessels were stained with a rat anti-mouse CD31 primary antibody (1:50, BD Pharmingen) followed by an anti-rat Alexa Fluor 549 (1:1000 Invitrogen). For proliferation, a rabbit monoclonal Ki67 antibody (1:500, clone SP6, Dako, Cambridge, UK) was detected with HRPconjugated anti-rabbit IgG (1:100, Dako). Antibody was visualized using the TSA biotin system (Perkin-Elmer, Waltham, MA, USA) followed by streptavidinconjugated Alexa Fluor 549 (1:1000, Invitrogen).

Vessel density was quantified as the number of blood vessels/field in five random viable fields $(10 \times$ objective) per tumor $(n=4-5$ per group). Proliferation was measured as the percentage of Ki67-positive area in relation to the DAPI-positive signal (tumor surface area) in five random viable fields $(10 \times$ objective) per tumors ( $n=4-5$ per group) using ImageJ software (version 1.38; NIH, Bethesda, MD, USA). Immunofluorescent images were acquired using the Leica DMRBE microscope with a Hamamatsu camera (Leica Microsystems Ltd, Milton Keynes, UK).

The effects of XRT and/or VE-822 on gut epithelium was determined by measuring changes in morphology $y^{33}$ and apoptosis ${ }^{32}$ of small intestine. Balb/c nude mice bearing PSN-1 tumors xenografts were treated with either vehicle or $60 \mathrm{mg} / \mathrm{kg}$ VE-822 p.o. at days 0,2 and 4. Mice $(n=3)$ were irradiated at day 0 using abdominal XRT ( $6 \mathrm{~Gy}$ ), $2 \mathrm{~h}$ after initiation of VE-822. At day 5 , mice were killed, and the small intestine was removed, washed and fixed in $3 \%$ formalin/PBS. Crosssections of the small intenstine were stained for hematoxylin and eosin and TUNEL (apoptosis), according to the manufacturer's instructions (Apoptag, Millipore, Watford, UK). Villus length was measured using ImageJ software (version 1.38). The loss of villus tip loss and the number of apoptotic cells were measured manually. Approximately 100 crypt-villus units were scored per group $(n=2)$.

SPECT imaging of $\gamma \mathrm{H} 2 \mathrm{AX}$ in pancreatic tumor xenografts. We recently established a non-invasive method for live animal imaging to detect phosphorylated $\gamma \mathrm{H} 2 \mathrm{AX}$ in response to DNA damage. ${ }^{34}$ This is based on administration of ${ }^{111}$ In conjugated to an anti- $\gamma \mathrm{H} 2 \mathrm{AX}$ antibody coupled to the cell penetrating peptide, Tat, to allow nuclear localization. SPECT imaging then reveals location and extent of $\gamma \mathrm{H} 2 \mathrm{AX}$ foci. ${ }^{34}$ Mice bearing PSN-1 tumor xenografts were treated with VE-822 $(60 \mathrm{mg} / \mathrm{Kg}$; days 0 and 1$)$ and XRT (6Gy; day 1), approximately $2 \mathrm{~h}$ after the second dose of VE-822. The radioimmunoconjugate ${ }^{111}$ In-DTPA-anti- $\gamma \mathrm{H} 2 \mathrm{AX}$-Tat was administered $2 \mathrm{~h}$ before radiation and SPECT was conducted at $24 \mathrm{~h}$ post-XRT as reported. ${ }^{34}$ Following this, mice were euthanized and selected organs were removed, weighed and counted for radioactivity. Volume of interest analysis was performed on reconstructed SPECT images using the Inveon Research Workplace software package (Siemens Medical Solutions, Surrey, UK). Results were expressed as a percentage of the injected dose per gram of tissue $(\% \mathrm{ID} / \mathrm{g})$.

Statistical analyses. The significance of differences between the means was measured by two-tailed $t$-test or one-way ANOVA (Bonferroni test) using the GraphPad Prism program version 4.0 (GraphPad Software, La Jolla, CA, USA). The values were expressed as means \pm S.D. A $P$-value $<0.05$ was considered statistically significant.

\section{Conflict of Interest}

JRP, PMR and PAC are full time employees of Vertex Pharmaceuticals (Europe), Ltd. and hold equity in Vertex Pharmaceuticals, Inc.

Acknowledgements. We thank Mick Woodcock, Sabira Yameen and Dr. Eric O'Neil for the technical expertise and Dr. Sally Hill, Karla Watson, Magda Flieger and Dr. Manuela Carvalho-Gaspar for the help with the animal work. This work was supported by grants from Vertex Pharmaceuticals as well as Cancer Research, UK, the Medical Research Council and the NIHR Biomedical Research Center, Oxford.

1. Hidalgo M. Pancreatic cancer. N Engl J Med 2010; 362: 1605-1617.

2. Raimondi S, Maisonneuve P, Lowenfels AB. Epidemiology of pancreatic cancer: an overview. Nat Rev Gastroenterol Hepatol 2009; 6: 699-708.

3. Ben-Josef E, Lawrence TS. Radiotherapy: the importance of local control in pancreatic cancer. Nat Rev Clin Oncol 2012; 9: 9-10.

4. Lim KH, Chung E, Khan A, Cao D, Linehan D, Ben-Josef E et al. Neoadjuvant therapy of pancreatic cancer: the emerging paradigm? Oncologist 2012; 17: 192-200.

5. Brunner TB, Scott-Brown M. The role of radiotherapy in multimodal treatment of pancreatic carcinoma. Radiat Oncol 2010; 5: 64. 
6. Stathis A, Moore MJ. Advanced pancreatic carcinoma: current treatment and future challenges. Nat Rev Clin Oncol 2010; 7: 163-172.

7. Jackson SP, Bartek J. The DNA-damage response in human biology and disease. Nature 2009; 461: 1071-1078.

8. Helleday T, Petermann E, Lundin C, Hodgson B, Sharma RA. DNA repair pathways as targets for cancer therapy. Nat Rev Cancer 2008; 8: 193-204.

9. Begg AC, Stewart FA, Vens $C$. Strategies to improve radiotherapy with targeted drugs. Nat Rev Cancer 2011; 11: 239-253.

10. Negrini S, Gorgoulis VG, Halazonetis TD. Genomic instability-an evolving hallmark of cancer. Nat Rev Mol Cell Biol 2010; 11: 220-228.

11. Jones S, Zhang X, Parsons DW, Lin JC, Leary RJ, Angenendt $P$ et al. Core signaling pathways in human pancreatic cancers revealed by global genomic analyses. Science 2008; 321: 1801-1806.

12. Ansari D, Rosendahl A, Elebro J, Andersson R. Systematic review of immunohistochemical biomarkers to identify prognostic subgroups of patients with pancreatic cancer. $\mathrm{Br} J$ Surg 2011; 98: 1041-1055

13. Okazaki T, Javle M, Tanaka M, Abbruzzese JL, Li D. Single nucleotide polymorphisms of gemcitabine metabolic genes and pancreatic cancer survival and drug toxicity. Clin Cancer Res 2010; 16: 320-329.

14. Chan DA, Giaccia AJ. Harnessing synthetic lethal interactions in anticancer drug discovery. Nat Rev Drug Discov 2011; 10: 351-364.

15. Reaper PM, Griffiths MR, Long JM, Charrier JD, Maccormick S, Charlton PA et al. Selective killing of ATM- or p53-deficient cancer cells through inhibition of ATR. Nat Chem Biol 2011; $7:$ 428-430.

16. Ruzankina Y, Schoppy DW, Asare A, Clark CE, Vonderheide RH, Brown EJ. Tissue regenerative delays and synthetic lethality in adult mice after combined deletion of Atr and Trp53. Nat Genet 2009; 41: 1144-1149.

17. Tao Y, Leteur $C$, Yang $C$, Zhang $P$, Castedo M, Pierre A et al. Radiosensitization by Chir124, a selective CHK1 inhibitor: effects of p53 and cell cycle checkpoints. Cell Cycle 2009; 8: $1196-1205$.

18. Toledo LI, Murga M, Zur R, Soria R, Rodriguez A, Martinez S et al. A cell-based screen identifies ATR inhibitors with synthetic lethal properties for cancer-associated mutations. Nat Struct Mol Biol 2011; 18: 721-727.

19. Murga M, Bunting S, Montana MF, Soria R, Mulero F, Canamero M et al. A mouse model of ATR-Seckel shows embryonic replicative stress and accelerated aging. Nat Genet 2009; 41: 891-898.

20. Sangster-Guity N, Conrad BH, Papadopoulos N, Bunz F. ATR mediates cisplatin resistance in a p53 genotype-specific manner. Oncogene 2011; 30: 2526-2533.

21. Nghiem P, Park PK, Kim Y, Vaziri C, Schreiber SL. ATR inhibition selectively sensitizes G1 checkpoint-deficient cells to lethal premature chromatin condensation. Proc Natl Acad Sci USA 2001; 98: 9092-9097.

22. Nghiem P, Park PK, Kim YS, Desai BN, Schreiber SL. ATR is not required for p53 activation but synergizes with p53 in the replication checkpoint. J Biol Chem 2002; 277: 4428-4434.

23. Murga M, Campaner S, Lopez-Contreras AJ, Toledo LI, Soria R, Montana MF et al. Exploiting oncogene-induced replicative stress for the selective killing of Myc-driven tumors. Nat Struct Mol Biol 2011; 18: 1331-1335.

24. Gilad O, Nabet BY, Ragland RL, Schoppy DW, Smith KD, Durham AC et al. Combining ATR suppression with oncogenic Ras synergistically increases genomic instability, causing synthetic lethality or tumorigenesis in a dosage-dependent manner. Cancer Res 2010; 70: 9693-9702.

25. Schoppy DW, Ragland RL, Gilad O, Shastri N, Peters AA, Murga M et al. Oncogenic stress sensitizes murine cancers to hypomorphic suppression of ATR. J Clin Invest 2012; 122 . 241-252.

26. Hammond EM, Giaccia AJ. The role of ATM and ATR in the cellular response to hypoxia and re-oxygenation. DNA Repair (Amst) 2004; 3: 1117-1122.

27. Pires IM, Olcina MM, Anbalagan S, Pollard JR, Reaper PM, Charlton PA et al. Targeting radiation-resistant hypoxic tumour cells through ATR inhibition. Br J Cancer 2012; 107: 291-299.

28. Prevo R, Fokas E, Reaper PM, Charlton PA, Pollard JR, McKenna WG et al. The novel ATR inhibitor VE-821 increases sensitivity of pancreatic cancer cells to radiation and chemotherapy. Cancer Biol Ther 2012; 13: 1072-1081.

29. Charrier JD, Durrant SJ, Golec JM, Kay DP, Knegtel RM, MacCormick S et al. Discovery of potent and selective inhibitors of ataxia telangiectasia mutated and Rad3 related (ATR) protein kinase as potential anticancer agents. J Med Chem 2011 54: $2320-2330$.
30. Charrier J-D, Durrant S, Kay D, Knegtel R, MacCormick S, Mortimore M et al. Pyrazine derivatives useful as inhibitors of ATR kinase and their preparation and use in the treatment of diseases. 2010; WO 2010071837 A1 20100624.

31. Martin NE, Brunner TB, Kiel KD, DeLaney TF, Regine WF, Mohiuddin M et al. A phase I trial of the dual farnesyltransferase and geranylgeranyltransferase inhibitor L-778,123 and radiotherapy for locally advanced pancreatic cancer. Clin Cancer Res 2004; 10: 5447-5454.

32. Potten CS, Merritt A, Hickman J, Hall P, Faranda A. Characterization of radiation-induced apoptosis in the small intestine and its biological implications. Int J Radiat Biol 1994; 65: 71-78.

33. Trier JS, Browning TH. Morphologic response of the mucosa of human small intestine to x-ray exposure. J Clin Invest 1966; 45: 194-204.

34. Cornelissen B, Kersemans V, Darbar S, Thompson J, Shah K, Sleeth K et al. Imaging DNA damage in vivo using gammaH2AX-targeted immunoconjugates. Cancer Res 2011; 71: 4539-4549.

35. Rodriguez R, Meuth M. Chk1 and p21 cooperate to prevent apoptosis during DNA replication fork stress. Mol Biol Cell 2006; 17: 402-412.

36. Sidi S, Sanda T, Kennedy RD, Hagen AT, Jette CA, Hoffmans R et al. Chk1 suppresses a caspase-2 apoptotic response to DNA damage that bypasses p53, Bcl-2, and caspase-3. Cell 2008; 133: 864-877.

37. Myers K, Gagou ME, Zuazua-Villar P, Rodriguez R, Meuth MATR. and Chk1 suppress a caspase-3-dependent apoptotic response following DNA replication stress. PLoS Genet 2009; 5: e1000324.

38. Frankenberg-Schwager M, Gebauer A, Koppe C, Wolf H, Pralle E, Frankenberg D. Singlestrand annealing, conservative homologous recombination, nonhomologous DNA end joining, and the cell cycle-dependent repair of DNA double-strand breaks induced by sparsely or densely ionizing radiation. Radiat Res 2009; 171: 265-273.

39. Vispe S, Cazaux C, Lesca C, Defais M. Overexpression of Rad51 protein stimulates homologous recombination and increases resistance of mammalian cells to ionizing radiation. Nucleic Acids Res 1998; 26: 2859-2864.

40. Huguet $F$, Andre $T$, Hammel $P$, Artru $P$, Balosso J, Selle $F$ et al. Impact of chemoradiotherapy after disease control with chemotherapy in locally advanced pancreatic adenocarcinoma in GERCOR phase II and III studies. J Clin Oncol 2007; 25: 326-331.

41. Schoppy DW, Ragland RL, Gilad O, Shastri N, Peters AA, Murga M et al. Oncogenic stress sensitizes murine cancers to hypomorphic suppression of ATR. J Clin Invest 2011; 122: 241-252.

42. Wilsker D, Bunz F. Loss of ataxia telangiectasia mutated- and Rad3-related function potentiates the effects of chemotherapeutic drugs on cancer cell survival. Mol Cancer Ther 2007; 6: 1406-1413.

43. Sangster-Guity N, Conrad BH, Papadopoulos N, Bunz F. ATR mediates cisplatin resistance in a p53 genotype-specific manner. Oncogene 2011; 30: 2526-2533.

44. Peasland A, Wang LZ, Rowling E, Kyle S, Chen T, Hopkins A et al. Identification and evaluation of a potent novel ATR inhibitor, NU6027, in breast and ovarian cancer cell lines. Br J Cancer 2011; 105: 372-381.

45. Brunner TB, Cengel KA, Hahn SM, Wu J, Fraker DL, McKenna WG et al. Pancreatic cancer cell radiation survival and prenyltransferase inhibition: the role of K-Ras. Cancer Res 2005; 65: 8433-8441.

46. Prevo R, Deutsch E, Sampson O, Diplexcito J, Cengel K, Harper J et al. Class I PI3 kinase inhibition by the pyridinylfuranopyrimidine inhibitor $\mathrm{PI}-103$ enhances tumor radiosensitivity Cancer Res 2008; 68: 5915-5923.

47. Fokas E, Yoshimura M, Prevo R, Higgins G, Hackl W, Maira SM et al. NVP-BEZ235 and NVP-BGT226, dual phosphatidylinositol 3-kinase/Mammalian target of rapamycin inhibitors, enhance tumor and endothelial cell radiosensitivity. Radiat Oncol 2012; 7: 48.

48. Workman P, Aboagye EO, Balkwill F, Balmain A, Bruder G, Chaplin DJ et al. Guidelines for the welfare and use of animals in cancer research. Br J Cancer 2010; 102: 1555-1577.

49. Fokas E, Im JH, Hill S, Yameen S, Stratford M, Beech J et al. Dual inhibition of the PI3K/ mTOR pathway increases tumor radiosensitivity by normalizing tumor vasculature. Cancer Res 2012; 72: 239-248.
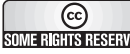

Cell Death and Disease is an open-access journal published by Nature Publishing Group. This work is licensed under the Creative Commons Attribution-NonCommercial-No Derivative Works 3.0 Unported License. To view a copy of this license, visit http://creativecommons.org/licenses/by-nc-nd/3.0/

\section{Supplementary Information accompanies the paper on Cell Death and Disease website (http://www.nature.com/cddis)}

